\section{Causes and Effects}

It is, of course, difficult to pinpoint the causes of academic corruption. In some societies, ingrained corrupt practices at all levels influence the universities, and inadequate salaries may be just part of a larger problem. Universities cannot be insulated from societal corruption. But the root cause in many developing and middle-income countries is related to academic salaries. If that problem were solved, it would be possible to deal with professorial corruption.

In most instances, universities are not corrupt institutions. They have strong traditions of meritocracy and shared academic values. But they cannot survive systematic starvation without ethics being damaged. Providing a living wage for the academic profession, as well as maintaining the core idea of the academic career, is a necessary prerequisite for an ethical academic culture.

\section{Promoting academic staff on the basis of seniority} alone, the practice in many countries, works against productivity.

Adequate salaries are, however, not enough. Well-paid professors are not always productive. A culture of productive academic work necessarily includes accountability, an internal ethic of hard work, a system of evaluation that includes an objective assessment of all kinds of academic work, and a merit-based system of promotion and salary allocation. Promoting academic staff on the basis of seniority alone, the practice in many countries, works against productivity.

The case of India is illustrative. Academic salaries for fulltime staff were increased several years ago to levels able to minimally support middle-class life, although at the same time, salaries for highly skilled professionals outside of the universities increased much faster. However, little was done to ensure productivity or accountability on campus. As a result, the campus culture in many universities and colleges of modest productivity, favoritism in appointments and promotions, and a lack of high academic standards remains despite salary improvements.

\section{CONCLUSION}

The current practice in many countries of asking academics to become entrepreneurs-by teaching in profit-making parallel programs, consulting, creating private companies, or focusing on contract research-in order to enhance their salaries may solve immediately funding shortfalls but it damages the longterm health of the university. Overreliance on part-time staffing means that there will be no one on campus who takes responsibility for the institution-there is no stability and no institutional commitment. These, and other, practices lead directly to academic corruption, not only forcing professors to enhance their incomes "by any means necessary" but also by jettisoning the traditional values and orientations of the university. The simple reality is that a healthy academic institution is an organic whole that requires adequate financial support, rigorous enforcement of traditional academic values, and at its core an academic profession committed to these values. Without this, corruption is likely to flourish and academic quality will inevitably suffer.

\section{International Student Experiences of Neo-Racism and Discrimination}

\section{JENNY J. LeE}

Jenny Lee is assistant professor in the Center for the Study of Higher Education at the University of Arizona. Address: 305 Education, University of Arizona, Tucson, AZ 85721. E-mail:JennyLee@u.arizona.edu.

W hile there is considerable investment and effort devoted to attracting international students, far less attention is paid to the experiences of international students once they arrive at the host institution. Thus, there remains little accountability and responsibility in place on institutions once they successfully attract the students they work so hard to recruit. There is limited literature on the international student experiences, and the problems associated with adjusting to a new environment. Some articles even offer a pathological diagnosis of international students as lacking coping skills. Far less research critically examines the inadequacies within host countries or institutions that perpetuate the difficulties for many international students. Understanding the experiences, especially the negative ones, of international students has been largely neglected but is central not only to ensuring their satisfaction but also fostering positive relationships between sending and receiving countries.

\section{International Students' Challenges}

A few studies have documented the tremendous hardships experienced by international students, not only in the United States but across the world-ranging from language and cultural barriers, feelings of isolation and loneliness, different ways of teaching and learning, and so on. However, most of these studies have framed these problems as stemming from an inability of these students to successfully "adapt" or "cope," which presumes that international students bear the sole responsibility to persist, overcome such challenges, and then blend into the host society. The underlying assumption is that 
host institutions are impartial and without fault and the primary burden is on the international students to navigate their ways through various cultural and institutional barriers. Few studies critically consider how institutions and individuals within these institutions may purposefully or inadvertently create a hostile climate that marginalizes international students.

\section{EXPERIENCES OF NEO-RACISM}

In a recent study of a research university in the southwestern region of the United States, we uncovered many disturbing examples of discrimination. Among our interviews with 24 students from I5 countries, we found that most of the students from Asia, Africa, Latin America, and the Middle East experienced at least some discrimination whereas none of the students from Europe, Canada, or Australia experienced any discrimination and were generally more satisfied with their decision to study in the United States. We examined these different experiences as evidence of neo-racism, or "new racism" on the basis of culture and national order. Beyond traditional racism, neo-racism justifies discrimination on the basis of cultural difference or national origin rather than by physical characteristics alone and appeals to "natural" tendencies to preserve group cultural identity-in this case the dominant group. Underlying neo-racism are notions of cultural or national superiority and an increasing rationale for marginalizing or assimilating groups in a globalizing world. In the case of international students, their experiences of discrimination were largely based on stereotypes and negative perceptions about their home countries rather than solely originating from the color of their skin. One of our informants from the Netherlands explained, “Well, I haven't experienced discrimination. But then again, I take a cynical view that I'm a White guy who speaks English. So that makes you less a target for discrimination. But if you're a non-White and you have troubles with the language then, yes, I suppose you can be even singled out."

Neo-racism can come in many forms, ranging from feelings of discomfort to verbal insults and direct confrontation. Many international students reported not only feeling unwelcome but also spoke of countless incidents of insulting jokes and statements about their home country, particularly Third World countries perceived as lacking basic resources-such as running water and adequate textbooks. Negative remarks were made not only by fellow students but also by faculty and administrators. For example, an international student described how a faculty member mentioned "wiping out the whole Middle East." Several others described reactions of frustration and contempt from faculty, students, and administrators for their language accents. Too often, a "foreign" accent, particularly Asian accents, was equated with "stupidity" and sometimes even ridiculed, whereas European accents were more tolerated and appreciated. Many international graduate students described how domestic students were favored over international students in securing teaching positions and the difficulties international students faced in securing academic jobs (i.e., research and teaching jobs) on campus. Other students recalled more overt forms of neo-racism, such as being yelled at to "go back to your country." International students also reported multiple accounts of sexual harassment, firing from jobs without just cause, and even physical attacks.

But perhaps most surprising and disheartening was that in most cases, these incidents were never reported in the past. As mentioned by one of our interviewees, "being international students, you get used to it." Beyond the actual cases of neoracism, we found that many international students also lack agency and awareness of their rights. Because many see themselves as temporary visitors, they did not feel that the rights of students applied to them. According to one of our informants, "As an international student, your rights are so few." Others kept silent because of fears about creating more trouble and possibly becoming at risk of losing their jobs and any financial support or being deported. One of our international students explained, "If you speak up you basically make it more difficult on yourself because they cut off your funding. . . . If you just

\section{Understanding the experiences, especially the nega-} tive ones, of international students has been largeIy neglected but is central not only to ensuring their satisfaction but also fostering positive relationships between sending and receiving countries.

toe the line then you get it really simple and easy." Several international students explained that while they noticed mistreatment from some faculty and administrators, they do not bother to file complaints or negative reports. Their reasoning is that faculty and administrators are above reproach, similar to the higher education system in their home countries or because they felt that unequal treatment and discrimination is the norm.

\section{CONCLUSION}

Despite such concerns, it is important to keep in mind that international education produces many benefits, not only for the institution and countries involved, but also for the individual students. The positive stories certainly outweighed the negative ones. But the purpose of this article is to shed light on the negative side of international study for many students, particularly those from countries viewed negatively by the host society.

All members of institutions should be made aware of the added challenges that international students face as well as institutions' responsibilities in creating a welcoming climate for all students, especially international students. Moreover, the difficulties that international students encounter need to 
be reframed as not solely a lack or inability of these students but as possible consequences of neo-racism within the host culture. The most common cases are subtle ones and may include "harmless" jokes about a foreign accent or culture, excluding international students from classroom participation and social events, and using dominant frames of reference that leave out other cultural perspectives.

Ultimately, successful international student exchange is not simply a headcount of international student enrollments but also involves the cultural and intellectual exchange of international students. This means paying greater attention to the experiences of those already enrolled and fostering positive, enriching interactions between international students and members of the host institutions.

\section{The Partnership for Higher Education in Africa}

\section{Narciso Matos}

Narciso Matos is chair of the International Development Program at the Carnegie Corporation of New York and former secretary general of the Association of African Universities and rector of the University Eduardo Mondlane, in Mozambique. E-mail: NMA@carnegie.org.

Tn 2000, the Ford Foundation, the John D. and Catherine T. 1 MacArthur Foundation, the Rockefeller Foundation, and the Carnegie Corporation of New York launched an initiative to coordinate their support of higher education in Africa: the Partnership for Higher Education in Africa (PHEA). Responding to, and contributing to, trends of democratization, public policy reform, and the increasing participation of civil society organizations in a growing number of African countries, the partnership aimed to support the priority given to education-especially the indispensable contribution of higher education to social and economic development. The foundations wanted to encourage the innovation and creativity witnessed in "universities on the move."

While maintaining each foundation's unique strategic focus, the four agreed to work together toward accelerating the processes of modernization and institutional revitalization of universities in selected African countries, committing \$IOO million over five years. The issues to be addressed included curriculum reform; training and retraining of faculty members and technical and support staff; participation of African experts in international research and scientific networks; improved internal governance and accountability; increased access for students and higher quality of academic activities; diversification of sources of universities' income and greater responsiveness to societal needs; and improved contribution to the alleviation of poverty.
To ensure that PHEA interventions address the priorities identified by leaders of higher education in Africa, the foundations have adopted a multilayered strategy. First, they selected seven countries-Ghana, Kenya, Mozambique, Nigeria, South Africa, Tanzania, and Uganda-that accentuated trends of democratization, public policy reform, participation of civil society organizations, priority of higher education, and innovative university leadership. These criteria do, unfortunately, omit countries and institutions that would qualify for support under other valid but less-stringent requirements.

Second, PHEA consulted with university leaders through such means as workshops organized to develop studies of their higher education systems. Local experts and scholars authored the studies, which were reviewed by leaders and experts from other partnership countries. This process has allowed members to benefit from the insight and guidance of African colleagues, has limited the negative influences of power imbalances stemming from foundations' control of financial resources, and has helped build a level of trust and comfort between foundations and African leaders.

Third, we have learned to celebrate accomplishments by attributing success to the agency of the grantees rather than to the foundations. Visibility is essential for successful interventions to encourage other African governments, donors and investment agencies to support higher education and to reassure the foundations' trustees and leaders that money is being effectively invested. On the other hand, too much publicity might raise the expectations of other needy institutions and countries, leading policymakers to steer resources away from partnership universities toward other pressing needs not presently addressed by donors.

Fourth, we decided that our investment should be allocated

While maintaining each foundation's unique strategic focus, the four agreed to work together toward accelerating the processes of modernization and institutional revitalization of universities in selected African countries, committing $\$ 100$ million over five years.

first and foremost to select African institutions, which would then identify partners in other countries and allocate resources for working with them. Admittedly, this decision is hard to enforce when many well-intentioned leaders and experts from the United States and other developed nations approach the partnership or individual foundations with truly valid and viable ideas. But to remain true to the principle of working directly with African institutions, even promising initiatives must be denied support.

An assessment of PHEA in 2005 revealed that since 2000 , the four foundations have invested \$150 million, 50 percent 